\title{
The Effect of Micro-Segregation on the Quantification of Microstructural Parameters in Grade 91 Steel
}

\author{
SHARHID JABAR, JOHN A. SIEFERT, MARTIN STRANGWOOD, \\ and GEOFF D. WEST
}

The quantification of key microstructural parameters as a function of aging or creep exposure time is commonplace in the assessment of 9Cr Creep Strength Enhanced Ferritic (CSEF) power-plant steels. In these studies, the sample is either assumed chemically homogenous at the micro-scale or that a material average will be achieved by collecting enough images at random locations. In this paper, the micro-scale chemical homogeneity of two ex-service boiler components, a pipe and a forging, are quantitatively assessed using high sensitivity chemical mapping from $\mu$-XRF. The compositional variation was as expected most pronounced in the larger elements $\mathrm{Mo}$ and $\mathrm{Nb}$, where a $>20$ pct difference in composition was present between positively and negatively segregated areas. The effect of this micro-segregation on local variations in Laves phase particle characteristics was investigated using SEM images. This showed a factor of two difference in the number of particles and the area coverage between positively and negatively Mo-segregated regions. This result was consistent with the thermodynamic equilibrium predictions of the phase content based on the observed level of segregation.

https://doi.org/10.1007/s11661-020-06062-y

(c) The Author(s) 2020

\section{INTRODUCTION}

SINCE the international energy crisis in the 1970s, increasing efforts have been made to improve the efficiency of power generation. ${ }^{[1]}$ An outcome of the drive for increased Fossil fuelled plant efficiency was the adoption and widespread design and fabrication of components using Grade 91 steel. This alloy is a creep strength enhanced ferritic (CSEF) steel that was originally developed over approximately a ten-year period beginning in the mid-1970s by the Oak-Ridge National Laboratory (ORNL) and Combustion Engineering. ${ }^{[2]}$ Extensions of this effort, and similar parallel studies in other parts of the world, have resulted in a family of martensitic CSEF steels otherwise referred to as 9 to 12 wt pet Cr CSEF steels. ${ }^{[3]}$ Gr.91 is the most widely used steel from this family of alloys due to its combination of corrosion and oxidation resistance, high thermal conductivity, a low thermal expansion coefficient and availability in the necessary product forms to fabricate complex components. ${ }^{[4,5]}$ It is commonly produced in a

SHARHID JABAR, MARTIN STRANGWOOD, and GEOFF D. WEST are with the WMG, University of Warwick, Coventry, CV4 7AL, UK. Contact e-mail: g.west@warwick.ac.uk JOHN A. SIEFERT is with the EPRI, $1300 \mathrm{~W}$ W.T.Harris Blvd, Charlotte, NC 28262.

Manuscript submitted August 6, 2020; accepted October 11, 2020.

Article published online November 15, 2020 wide variety of product forms including seamless pipe (ASTM A335 P91), ${ }^{[6]}$ seamless tubes (ASTM A213 T91), ${ }^{[7]}$ forgings (ASTM A182 F91), ${ }^{[8]}$ plate (ASTM A335 Gr. 91), ${ }^{[6]}$ and castings (ASTM A217 C12A), ${ }^{[9]}$ among others.

After shaping, P91 components are subjected to a series of normalizing and tempering heat treatments carried out in the temperature ranges of $1040^{\circ} \mathrm{C}$ to 1080 ${ }^{\circ} \mathrm{C}$ and $730{ }^{\circ} \mathrm{C}$ to $800{ }^{\circ} \mathrm{C}$, respectively. ${ }^{[6]}$ The intent of this heat treatment cycle is to form a uniform tempered martensitic structure strengthened by three primary mechanisms: 1) solid solution strengthening via Mo alloying, 2) dislocation strengthening via the tempered martensite matrix, and 3 ) precipitation strengthening via (Fe, Cr) $\mathrm{M}_{23} \mathrm{C}_{6}$-type carbides and $(\mathrm{V}, \mathrm{Nb})(\mathrm{N}, \mathrm{C}) \mathrm{MX}$-type carbo-nitrides. ${ }^{[10]}$ When $\mathrm{P} 91$ and other 9 to $12 \mathrm{wt}$ pet $\mathrm{Cr}$ components are subjected to elevated operating temperature $\left(\sim 550^{\circ} \mathrm{C}\right)$, the precipitation of other phases may occur (which are not formed during tempering). These include the Mo-rich Laves intermetallic phase $\left(\mathrm{Fe}_{2} \mathrm{X}\right)$ where $\mathrm{X}$ signifies $\mathrm{Mo} / \mathrm{W}$ and the modified Z-phase $(\mathrm{Cr}(\mathrm{V}, \mathrm{Nb}) \mathrm{N})$. Z-phase in these steels is well known for its detrimental effect on creep performance as it forms at the expense of smaller MX particles, which results in net lower precipitation strengthening. Z-phase is not often reported in $9 \mathrm{wt}$ pct $\mathrm{Cr}$ steels, this is likely because it is only observed after extended aging times $(>30,000 \mathrm{hrs})$ even at relatively high temperatures $\left(\right.$ e.g., $\left.650{ }^{\circ} \mathrm{C}\right) .{ }^{[1-13]}$ 
The intermetallic Laves phase is known to precipitate and grow early during high-temperature exposure through the segregation of $\mathrm{Mo}$ and $\mathrm{Si}$ to martensite lath boundaries located next to $\mathrm{M}_{23} \mathrm{C}_{6}$ carbides. ${ }^{[14]}$ Similarly, it was also found in a martensitic steel (TAF650) that $\mathrm{Fe}_{2} \mathrm{~W} / \mathrm{Mo}$ Laves particles were precipitating on $\mathrm{M}_{23} \mathrm{C}_{6}{ }^{[15]}$ The formation of Laves phase will result in a loss of solid solution strengthening from $\mathrm{W} /$ Mo. The precipitation strengthening from Laves phase in these steels is likely to be limited because it coarsens rapidly at normal service temperatures (e.g., $\sim 570{ }^{\circ} \mathrm{C}$ ) for these materials, ${ }^{[12]}$ although if coarsening can be restricted (e.g., exposure to lower temperatures) some benefits to creep strength have been reported. ${ }^{[16,17]}$ Furthermore, many researchers have linked cavity nucleation in Gr.91 steel to coarse Laves phase particles. ${ }^{[12,18-20]}$ This includes Lee et al. who suggested that a ductile-to-brittle transition occurred when the average diameter of grain boundary Laves phase particles coarsened to $130 \mathrm{~nm}$ in an ASTM Grade 92 steel. Premature creep failure has been associated with a change from transgranular to intergranular failure mode. ${ }^{[19]}$

Energy Filtered Transmission Electron Microscopy (EF-TEM)-based quantification of Laves phase in the German grade X12CrMoWVNbN10-1-1 creep tested at 600 and $650{ }^{\circ} \mathrm{C}$ by Hofer et al. showed no significant influence of stress on the average size of Laves particles ( 5 pct increase). ${ }^{[21]}$ In the same study, only $\mathrm{M}_{23} \mathrm{C}_{6}$ was reported to show a pronounced increase in average size. Using the same steel with Scanning Electron Microscope-based Back-Scattered Electron (BSE) imaging techniques, Dimmler et al. found a significantly lower median value of particle size for the Laves phase. ${ }^{[16]}$ This discrepancy was attributed to the much larger area that was analyzed with the SEM BSE imaging, providing better statistical quantification of the full size range of Laves particles. ${ }^{[16,17]}$ In both studies, the area fraction of Laves phase tended to increase after longer times of exposure at both 600 and $650{ }^{\circ} \mathrm{C}$ temperatures, however, the number of particles decreased, indicating the particles were much coarser for longer times of exposure. ${ }^{[16,21]}$

Most of the heat treatments for Gr.91 are based on the bulk composition, but solidification of the alloy into shaped, e.g., turbine casings, or semi-finished, e.g., ingots, products introduces potential chemical segregation (both micro- and macro-). Gr.91 contains many elements which, during solidification, partition preferentially into the liquid ( $\mathrm{Al}$ is the exception). The level of segregation depends on i) composition, e.g., strong carbide formers such as $\mathrm{Cr}$ and Mo show greater segregation when $\mathrm{C}$ is also present and partitioning, and ii) processing history, e.g., solidification rates and post-casting thermo-mechanical treatments. The scale of segregation-both the difference between maximum and minimum concentrations and the spatial separation between positively and negatively segregated regionsdecreases with increasing thermal exposure and mechanical deformation at temperatures where solid-state diffusion can occur.
Recently, the effects of segregation have been studied by Sawada et al. ${ }^{[22]}$ on Gr.91 (T91) steel. They investigated the effect of $\mathrm{Cr}$ micro-segregation on the overall creep strength and implied that it led to a shorter time to rupture compared to more compositionally homogenous heats. For several uniaxial creep tests, the variation in $\mathrm{M}_{23} \mathrm{C}_{6}$ particle densities and hardness were also correlated to the segregation present. ${ }^{[22]}$ Wang et al. also found a variation of hardness along directionally solidified bars of CB2 steel due to the macro-segregation of $\mathrm{B}, \mathrm{C}, \mathrm{Nb}, \mathrm{P}, \mathrm{Cr}, \mathrm{Mo}, \mathrm{Si}, \mathrm{V}$, and $\mathrm{Mn}$ in steel. ${ }^{[23]}$ The effect of interdendritic enrichment of $\mathrm{C}, \mathrm{Cr}, \mathrm{Mn}$, and $\mathrm{Ni}$ has also been associated with the likelihood of retained austenite in P91 weld deposits by Santella et al. ${ }^{[24]}$ The theory of the cause and effect of macro- and micro-segregation has been studied in depth ${ }^{[25,26]}$ but the implications have yet to be systematically researched in 9 to 12 wt pct $\mathrm{Cr}$ martensitic boiler steels. It is particularly important to link the potential segregation to large area, relevant microstructural quantification since many studies continue to rely on 'basic' methods for investigating complex martensitic microstructures. Reliable quantitative microstructural data are also required to feed into creep damage models for these materials. [27]

It is clear that micro-segregation can have significant effects in other steel types such as those detailed for high-strength low-alloy (HSLA) steels ${ }^{[28-30]}$ and in automotive grades, ${ }^{[31]}$ where the effects of segregation on precipitation and grain structure affecting properties and property scatter have been identified. In the case of HSLA steels, a study by Wang et al. regarding the segregation of $\mathrm{Nb}$ showed a subsequent formation of an increased amount of $\mathrm{Nb}$-rich precipitates in the interdendritic regions resulting in a banded microstructure with a bimodal grain size distribution. ${ }^{[28]}$ Bimodal grain size distributions do not affect properties such as hardness significantly, but do affect crack resistance properties. ${ }^{[32]}$ Regarding C-Mn automotive steels, Slater et al. found a Mn-segregated steel sample which only showed a partially recrystallized microstructure for the same holding times of an unsegregated sample. ${ }^{[31]}$ In both examples, the objective was to investigate the variations in mechanical properties due to inhomogeneous compositions and microstructures. The objective of this paper is to study the implications of micro-segregation of Mo and its effect on the quantification of the intermetallic Laves phase in Cr.91 steel, a key detail that to the author's knowledge has not been previously appreciated or studied.

\section{EXPERIMENTAL PROCEDURE}

The Gr.91 materials used in this study were from an ex-service final superheat outlet header (Figure 1(a)), supplied by the Electric Power Research Institute (EPRI). The components were operated for 79,000 hours at a bulk steam outlet temperature and pressure of $570{ }^{\circ} \mathrm{C}$ and $16.5 \mathrm{MPa}$, respectively. The subsequent samples analyzed in this study were taken from a 
seamless pipe (Barrel section 2 in Figure 1(a)) section manufactured to A-/SA-335 P91 and designated as B2 (Figure 1(b)) and a second sample from a forged tee-piece (Tee-piece 1 in Figure 1(a)) manufactured to A-/SA-182 F91 designated as TP1 (Figure 1(c)). Double-notched creep test bars were machined from these ex-service materials and were tested at $625^{\circ} \mathrm{C}$ with a net section stress of $100 \mathrm{MPa}$ at the notch root. By comparison, the net section stress in the gauge section was $50 \mathrm{MPa}$. Details of the samples are provided in Table I. The compositions of the two sections were measured using ICP-OE/MS combustion and IGF by Dirats laboratories (Westfield MA), and is documented in Table II. This steel was produced to the ASTM/ ASME requirements in the early 1990s allowing for a maximum aluminum (Al) content of $0.04 \mathrm{wt}$ pet (later reduced to $0.02 \mathrm{wt} \mathrm{pct}){ }^{[6]}$

Post-tested samples were sectioned along the axis of the bars including the failed notch, the unfailed notch, gauge section, transition, and head (Figure 1). Samples were prepared using standard metallographic procedures, including mounting in conductive bakelite resin, grinding until flat, and polishing down to a $3 \mu \mathrm{m}$ finish using diamond polishing suspensions. The final polishing step was performed with a $0.02 \mu \mathrm{m}$ alumina suspension to ensure a deformation-free surface finish.
For the characterization of these materials, a centimeter-to-micrometer level characterization process was applied. At the centimeter length scale, the elemental distribution of the two steel samples was evaluated using a Bruker M4 Tornado micro-X-Ray Fluorescence $(\mu$-XRF) system. The system is equipped with two 30 $\mathrm{mm}^{2}$ EDS detectors, the chemical maps were collected using a $20 \mu \mathrm{m}$ spot size, $50 \mathrm{kV}$ accelerating voltage, and a current of $600 \mathrm{~mA}$ all while under vacuum. An AlTi $100 / 25$ filter was used to reduce diffraction peaks, quantitative data was collected using a quantification algorithm within the Bruker software, which implements a background subtraction from all spectra in the map. Each map was collected with a pixel dwell time of $50 \mathrm{~ms}$ to ensure that statistically robust quantitative data could be extracted from even small areas of the maps.

Based on the $\mu$-XRF quantitative maps, areas of interest were analyzed at higher spatial resolution using Scanning Electron Microscopy (SEM). A JEOL 7800F field emission gun SEM (FEG-SEM) was used for two purposes; a) Energy Dispersive Spectroscopy (EDS) map acquisition using an Oxford Instruments Ultimax $100 \mathrm{~mm}^{2}$ detector and b) imaging using a solid-state back-scattered electron (BSE) detector. Large-area EDS maps ( $1 \mathrm{~mm}$ horizontal field width) were collected at $10 \mathrm{kV}$ for extended exposure time periods ( $\sim 8$ hours) at high count rates $(>200,000$ input cps) to maximize the
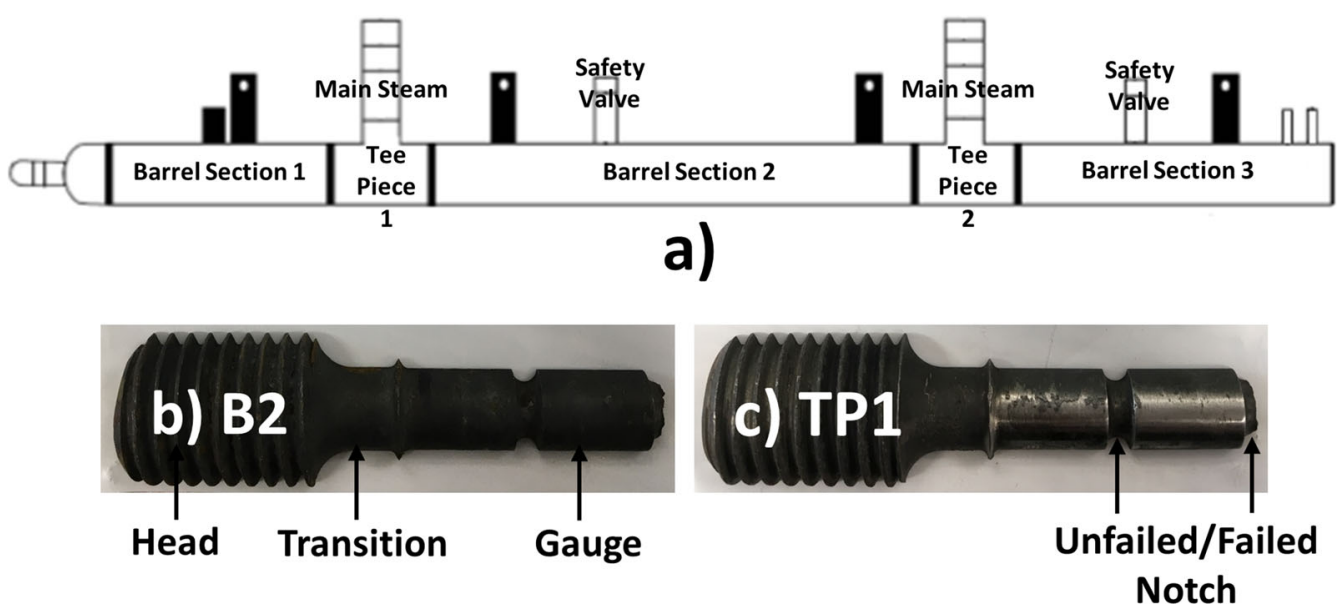

Fig. 1-Diagram of the Grade 91 superheat outlet header $(a)$ and failed double notch creep bars B2 $(b)$ and TP1 (c) which were machined (and tested) from the ex-service header.

Table I. Accelerated Creep Test Conditions and Performance of Steels B2 and TP1

\begin{tabular}{llccc}
\hline & & \multicolumn{2}{c}{ Test Conditions } \\
\cline { 3 - 5 } Material ID & Type of Test & Temp. $\left({ }^{\circ} \mathrm{C}\right)$ & $\begin{array}{c}\text { Stress at Gauge }(\mathrm{MPa}) \\
(\text { *at Notch Root) }\end{array}$ & $\begin{array}{c}\text { Time to Failure } \\
(\mathrm{h})\end{array}$ \\
\hline B2 & Type 1 Double Notch Bar & 625 & $100^{*}$ & $\sim 50$ \\
TP1 & Type 1 Double Notch Bar & 625 & $100^{*}$ & 6,714 \\
\hline
\end{tabular}


sensitivity of the SEM-EDS for elemental distribution mapping. BSE-SEM images were collected at $5 \mathrm{kV}$, at a working distance of $\sim 10 \mathrm{~mm}$, and in specified locations to measure the size distribution, population, and area coverage of the Laves phase particles.

Laves phase particles have very strong atomic number (Z) contrast with the steel matrix and any other particles (e.g., $\mathrm{M}_{23} \mathrm{C}_{6}$ ), making them easily distinguishable and analyzed using image analysis software. Three sets of images were collected and analyzed, at a $20 \mu \mathrm{m}$ horizontal field width, for each of the two steel samples. The first set in each section consisted of 20 images systematically positioned across the sample at every millimeter along two horizontal lines separated by more than $10 \mathrm{~mm}$, these sets of data will be referred to as systematically collected random areas (SCRA). The second and third set of images consisted of 5 images in positively and negatively Mo-segregated regions. Images were processed using the open-source image analysis software ImageJ, and each image was collected with a resolution of $2560 \times 1920$ pixels. For the Laves phase particle measurements, a truncation correction factor was not applied due to the low interaction depth of $5 \mathrm{kV}$ electrons in steel, furthermore, any particles below 40 $\mathrm{nm}$ were eliminated from analysis due to the overlap of noise artifacts from thresholding.

Equilibrium simulations were performed using Thermo-Calc and the TCFE version 9 database. The values of the elements inputted came from a combination of EDS measurements ( $\mathrm{Cr}, \mathrm{V}, \mathrm{Nb}$, and $\mathrm{Mo})$ and the bulk composition analysis ( $\mathrm{Mn}, \mathrm{Al}, \mathrm{Si}, \mathrm{N}$, and $\mathrm{C}$ ) from Table II with the balance attributed to Fe.

Although the creep test parameters are provided for completeness, only head sections are analyzed in this paper. The original rationale for these creep tests was to be able to understand the very different creep behavior of two different sections of the same ex-service component on a microstructural level. However, an important part of making quantitative microstructural measurements is to understand quantitatively area-to-area variations, which is the subject of this paper.

\section{RESULTS AND DISCUSSION}

\section{A. Centimeter-Scale Chemical Homogeneity of Samples}

Figures 2 and 3 show $\mu$-XRF-derived chemical distribution maps of a $42 \mathrm{~mm}^{2}$ head section cut along the gauge length of the creep test bar for samples B2 and TP1, respectively. Although chemical segregation is observed in both samples, the pattern of segregation is very different. In B2, chemical banding along the axis of the creep bar is observed. These bands are typically between 0.5 and $2 \mathrm{~mm}$ in length and are approximately 20 to $50 \mu \mathrm{m}$ wide, dimensions which are consistent with the reported literature for rolled/drawn interdendritic micro-segregation. ${ }^{[23,31]}$ In TP1, the segregation exists in non-directional diffuse "clouds" which are typically 0.2 to $1 \mathrm{~mm}$ in length and 0.2 to $1 \mathrm{~mm}$ in width. These clouds are localized in specific regions rather than spread homogeneously across the sample like B2. The differences in segregation behavior of the two samples can be attributed to their different forming processes and their effects on the interdendritic regions from casting; B2 is from a drawn pipe (axis of the creep test bar is along the drawing direction) and TP1 is from a forging.

The local extremes of composition for both samples are compared together with the average measured using $\mu$-XRF and from the bulk chemical analysis in Table III. In this work, positive segregation is used to describe regions where the alloying element content (e.g., Mo, Cr, Nb, and $\mathrm{V}$ ) is above the bulk value of the steel, and conversely negative segregation is used for areas where the alloying element content is below the bulk value of the steel. It is noteworthy that the value obtained using the standard-less $\mu$-XRF technique is close in absolute terms to the bulk composition measured by the commercial test house for the elements considered in Table II. (It should be noted that the $\mu$-XRF technique does not have the sensitivity to detect trace impurities in these steels due to diffraction effects, and elements with a $\mathrm{Z}<\mathrm{Na}$ due to $\mathrm{X}$-ray absorption from the $\mathrm{Be}$ windows on the EDS detectors.) It is important to note that $\mathrm{Nb}$ and $\mathrm{Mo}$ had the largest proportional variation in relative concentration from all the major alloying elements (as expected from their equilibrium partition coefficients and carbide-forming nature). For example, Mo showed a difference of $\sim 24$ and $\sim 38$ pct between positively and negatively segregated regions in $\mathrm{B} 2$ and $\mathrm{TP} 1$, respectively, comparatively $\mathrm{Cr}$ showed a difference of $\sim 4$ and $\sim 10$ pct, respectively. While it is possible to simulate segregation in complex alloys, ${ }^{[27]}$ the non-equilibrium nature of segregation means that the level recorded here will depend on the casting conditions and the cumulative effects of heating and deformation (through dissolution and diffusion processes) during shaping. These data are not available and so this study relates quantified Laves phase parameters to the measured local compositions (segregated).

Although Figures 2 and 3 were collected in the head section of the samples, similar results were observed in the corresponding gauge sections. There was no observed necking aside from a very localized region in the notch and the applied temperature for the test $\left(625^{\circ} \mathrm{C}\right)$ is much too low to homogenize the composition of the sample.

\section{B. The Effect of Segregation on the Quantification of Microstructural Features}

Figure 4 shows a typical SEM image and the accompanying EDS spectra collected from a bright phase particle. The $\mathrm{Si}$ and Mo content of this particle is consistent with Laves phase. ${ }^{[14]}$ Similar spectra were found in positively and negatively segregated regions of both samples. Although these materials contain a number of second phase particles, Laves phase $\left(\mathrm{Mo}_{2} \mathrm{Fe}\right)$ was chosen to assess the effect of segregation on the quantification of microstructural features because the segregation of Mo (a major constituent of Laves phase) 
Table II. Chemical Compositions of Steels B2 and TP1 with Regard to the ASTM A335 Composition Standard (Fe = Balance)

\begin{tabular}{|c|c|c|c|c|c|c|c|c|c|c|}
\hline Sample & $\mathrm{Al}$ & $\mathrm{C}$ & $\mathrm{Cr}$ & $\mathrm{Mn}$ & Mo & $\mathrm{N}$ & $\mathrm{Nb}$ & $\mathrm{Ni}$ & $\mathrm{P}$ & $\mathrm{S}$ \\
\hline A335 Min & - & 0.08 & 8.00 & 0.30 & 0.85 & 0.030 & 0.06 & - & - & - \\
\hline A335 Max & 0.02 & 0.12 & 9.50 & 0.60 & 1.05 & 0.070 & 0.10 & 0.40 & 0.20 & 0.010 \\
\hline B2 & 0.04 & 0.10 & 8.77 & 0.41 & 0.94 & 0.0454 & 0.071 & 0.12 & 0.009 & 0.010 \\
\hline TP1 & 0.02 & 0.10 & 8.30 & 0.40 & 0.94 & 0.0424 & 0.070 & 0.19 & 0.012 & 0.002 \\
\hline Sample & $\mathrm{Si}$ & $\mathrm{Ti}$ & $\mathrm{V}$ & As & $\mathrm{B}$ & $\mathrm{Cu}$ & $\mathrm{O}$ & $\mathrm{Pb}$ & $\mathrm{Sb}$ & $\mathrm{Sn}$ \\
\hline A335 Min & 0.20 & - & 0.18 & - & - & - & - & - & - & - \\
\hline A335 Max & 0.5 & 0.01 & 0.25 & - & - & - & - & - & - & - \\
\hline B2 & 0.41 & 0.002 & 0.224 & 0.0128 & - & 0.19 & 0.0043 & 0.00075 & 0.0023 & 0.0080 \\
\hline TP1 & 0.33 & 0.002 & 0.214 & 0.0042 & $<0.0003$ & 0.05 & 0.0018 & 0.00003 & 0.00063 & 0.0030 \\
\hline
\end{tabular}
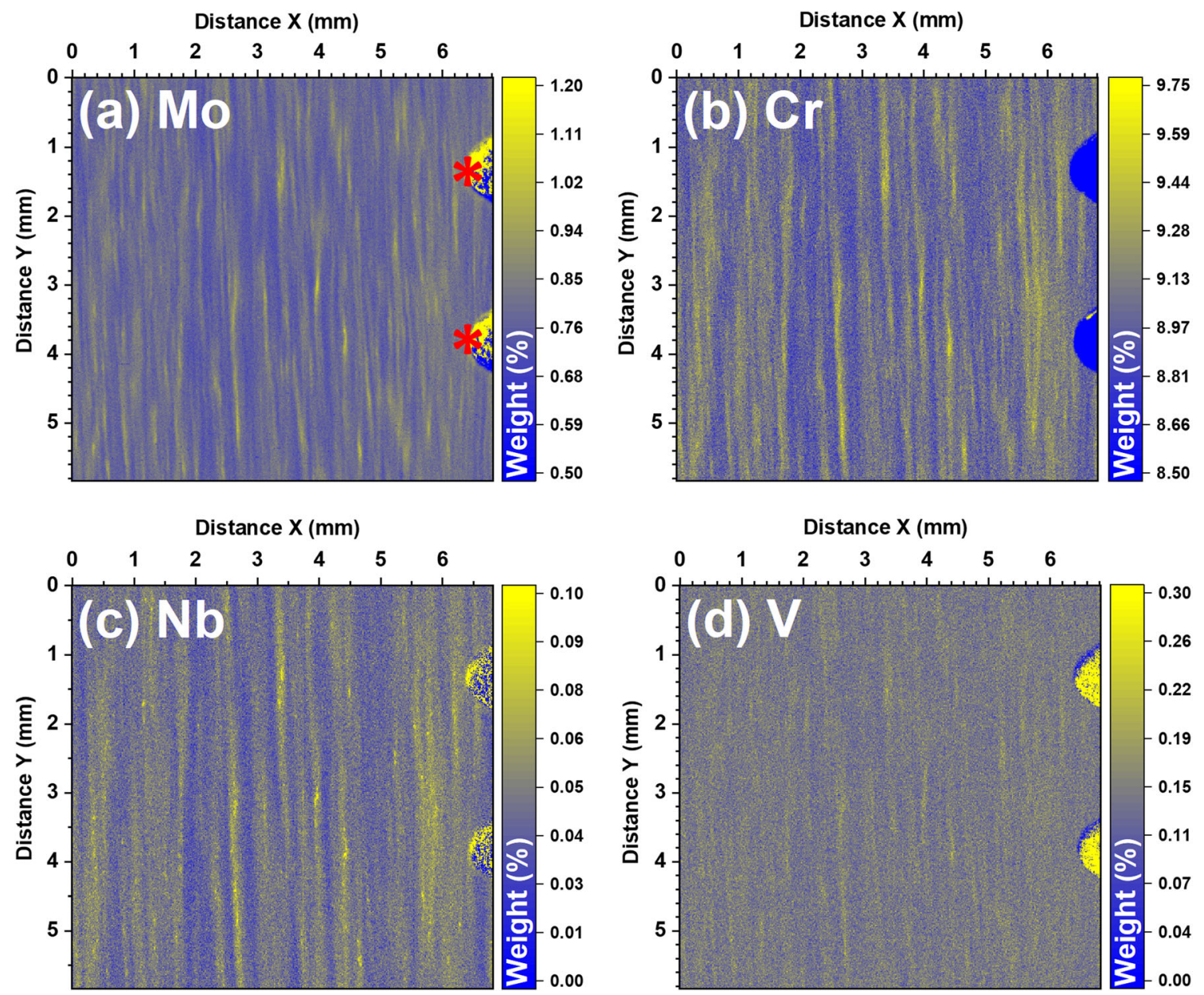

Fig. 2- $-\mathrm{X}$ XRF chemical distribution maps of steel B2 from the head section, highlighting the chemical inhomogeneity in some of the major alloying elements $(a) \mathrm{Mo}(b) \mathrm{Cr}(c) \mathrm{Nb}(d) \mathrm{V}$.

is high relative to other alloying elements (e.g., $\mathrm{Cr}$ and V). Furthermore, Laves phase is relatively straight forward to quantify in the SEM for the current steels of interest due to the approximate range in particle diameter (40 to $\sim 1000 \mathrm{~nm}$ ) and the high number per unit area (typically $>100,000$ particles per $\mathrm{mm}^{2}$ ). This permitted a full size distribution to be collected and analyzed in a time-efficient and to a statistically relevant procedure.
In the literature, there are many studies detailing the quantification of Laves phase particles using back-scattered electron imaging in the SEM. ${ }^{[12,16,17]}$ In these studies, the effect of local chemical differences are minimized by collecting multiple images to get an average over the sample. A similar systematic approach was used here to collect 20 images across the head section of both samples. The images were processed to show the variation in area content of Laves phase across 

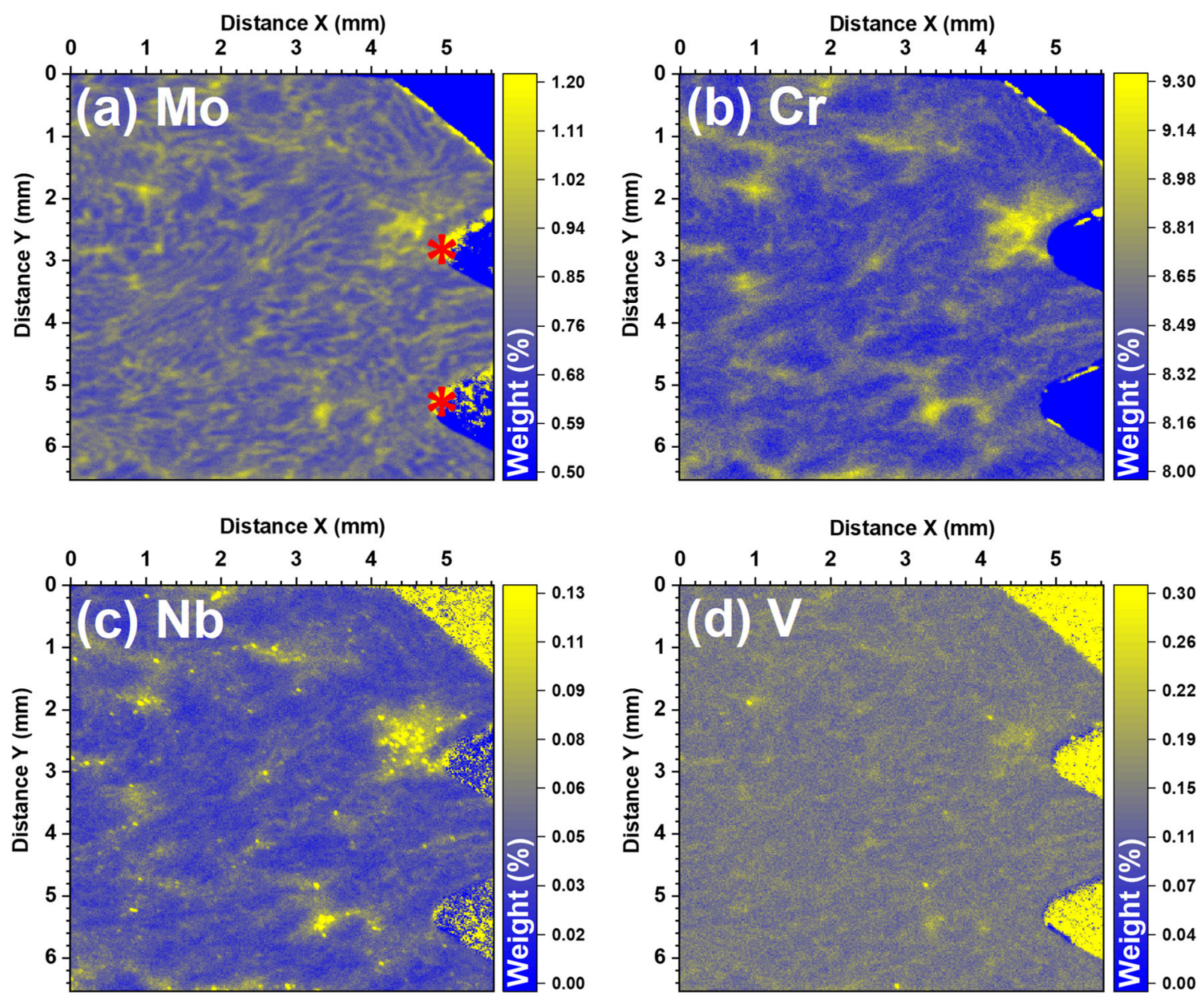

Fig. 3- $\mu$-XRF chemical distribution maps of steel TP1 from the head section, highlighting the chemical inhomogeneity in some of the major alloying elements $(a) \mathrm{Mo}(b) \mathrm{Cr}(c) \mathrm{Nb}(d) \mathrm{V}$.

Table III. Quantitative Chemical Composition Data Acquired from Figs. 1 and $2(\mu$-XRF)

\begin{tabular}{llllll}
\hline \multirow{2}{*}{ Sample } & & \multicolumn{4}{c}{ Concentration $(\mathrm{Wt} \mathrm{Pct}) \mathrm{Fe}=$ Balance } \\
\cline { 3 - 6 } & Area & $\mathrm{V}$ & $\mathrm{Cr}$ & $\mathrm{Nb}$ & $\mathrm{Mo}$ \\
\hline B2 & high & 0.19 & 9.35 & 0.07 & 0.94 \\
& low & 0.16 & 8.97 & 0.05 & 0.76 \\
& average & 0.16 & 9.02 & 0.06 & 0.82 \\
& Table II & 0.224 & 8.77 & 0.071 & 0.94 \\
TP1 & high & 0.21 & 9.21 & 0.10 & 1.08 \\
& low & 0.16 & 8.34 & 0.05 & 0.78 \\
& average & 0.16 & 8.45 & 0.05 & 0.81 \\
& Table II & 0.214 & 8.30 & 0.070 & 0.94 \\
\hline
\end{tabular}

Showing the variation of elements in the positively (high) and negatively (low) segregated regions as well as the average ( $\mu$-XRF) compositions in comparison to Table II (ICP-OE/MS) provided.

the data set as shown in Figure 5 (SCRA analysis). The range in area coverage across the data set is from 0.51 to 1.25 pet in $\mathrm{B} 2$ and from 0.32 to 0.77 pct for TP1. It is tempting to simply attribute this variation to sampling factors such as the relatively low number of particles per image (31 to 55 for B2 and 17 to 51 for TP1) and/or local variations in boundary type on which these particles preferentially precipitate. Typical investigations would overcome this by combining the images together to yield an average coverage. Alternatively, the possible statistical variation between images can be reduced simply by decreasing the magnification so that more particles per image are collected. This was not done here for two reasons:

(i) The area analyzed needed to be smaller than the segregation band width so that variation due to local changes in composition could be determined, and

(ii) A magnification at which all Laves particles could be detected was chosen so that the full size range of particles could be considered in the analysis.

This allows the contribution that segregation has on the image-to-image variation to be quantitatively assessed as in the following sections. 

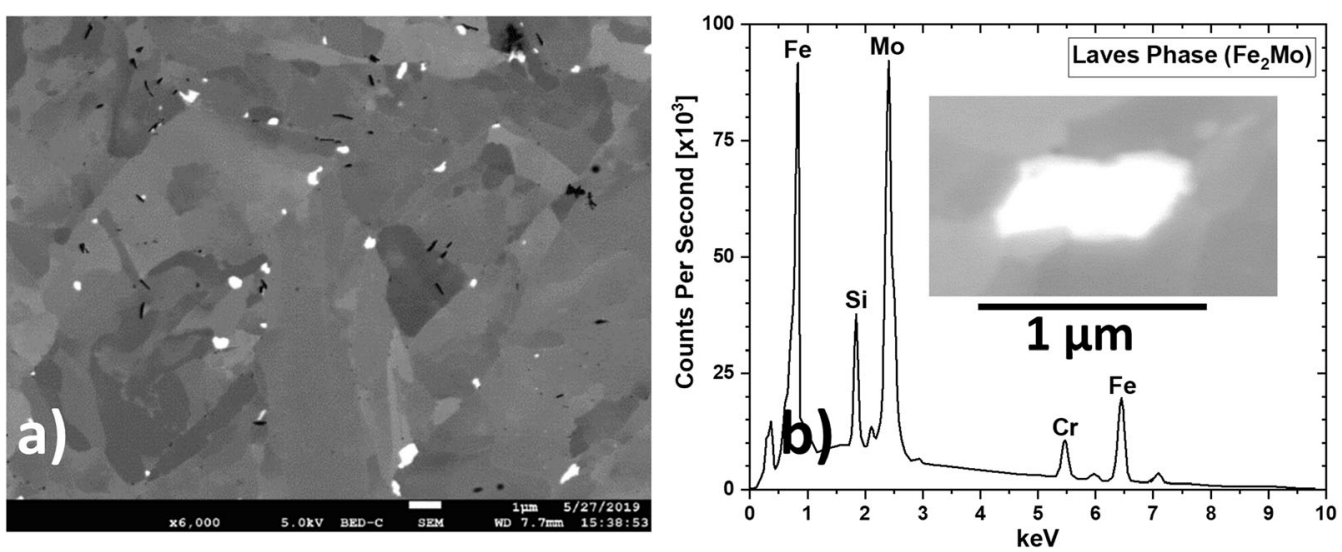

Fig. 4-A typical BSE-SEM image of sample B2 showing the bright Laves phase particles $(a)$ and a typical EDS spectra obtained from the center of the inset bright Laves phase particle $(b)$.

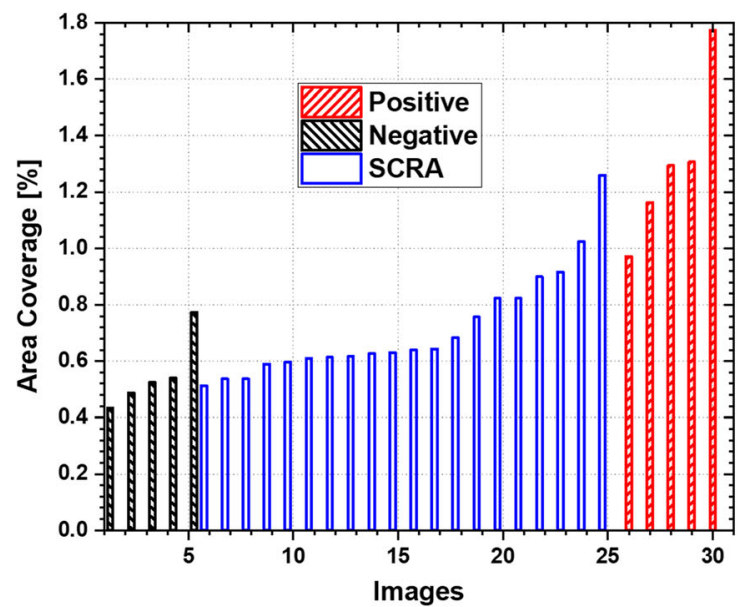

(a)

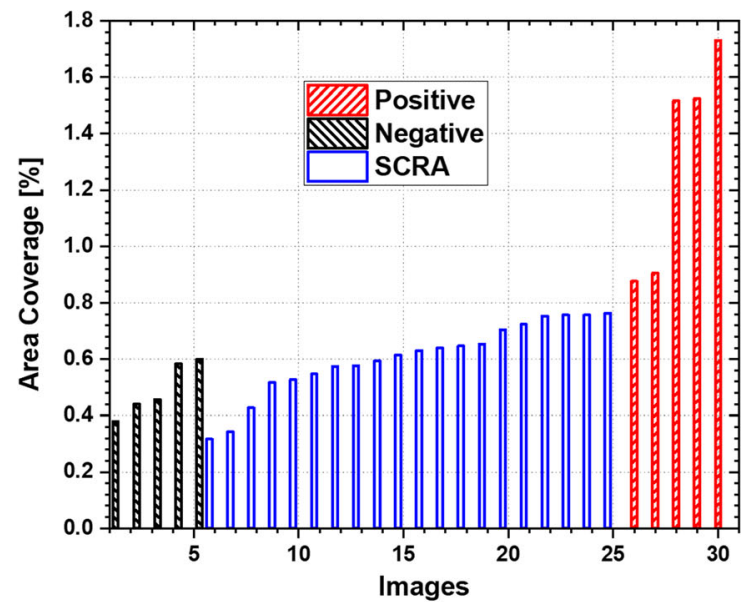

(b)

Fig. 5-The variation in area coverage of the Laves phase in each image of steel $(a)$ B2 and (b) TP1 with regard to sampling areas.

\section{B2}

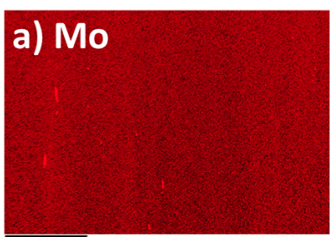

$250 \mu \mathrm{m}$

e) Mo

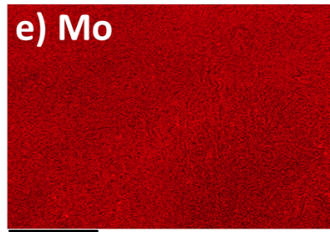

$250 \mu \mathrm{m}$

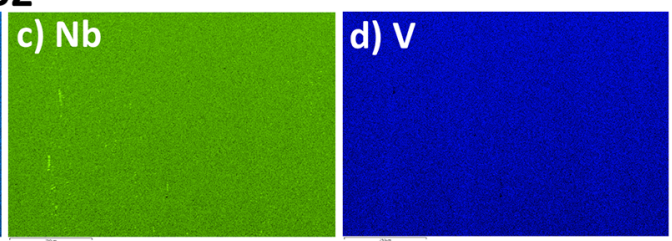

TP1
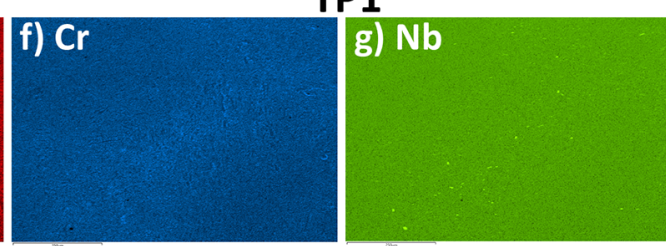

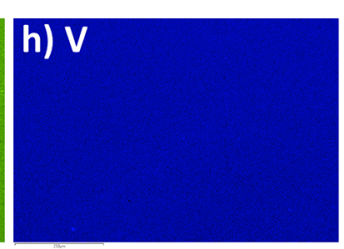

Fig. 6-FEG-SEM-EDS maps for steels B2 $(a$ to $d)$ and TP1 (e to $h)$, highlighting the chemical inhomogeneity in some of the major alloying elements. 


\section{Quantification of Laves Phase in Targeted Areas}

To study the effect of micro-segregation on Laves phase particle population characteristics, the chemical variations observed using $\mu$-XRF needed to be found within an SEM. This was achieved by locating the approximate area based on their proximity to features within the XRF maps (i.e., the screw threads machined into the head sections - red asterisk in Figures 2 and 3). The chemical composition was then measured in these approximate areas using SEM-EDS maps at low magnification, long dwell time, and high count rate. Figure 6 shows typical SEM-derived EDS maps for both B2 and TP1 samples. The local range in composition was extracted from these maps and compared with the compositional variations measured using $\mu$-XRF in Table IV. In all samples and all areas, the compositional extremes measured within the maps are lower in SEM-EDS than with $\mu$-XRF. This is to be expected since the $\mu$-XRF scans were performed over a much larger area providing many more positively segregated bands from which to select the highest and lowest areas. Even where the same area is studied from both techniques, the much larger interaction volume of $\mu$-XRF at $50 \mathrm{kV}$ compared with SEM-EDS at $10 \mathrm{kV}$ would be expected to yield result differences. From the SEM-EDS maps, a series of 5 images were collected in both positively and negatively Mo-segregated areas. Typical examples of BSE-SEM images collected from these areas in the head section of both samples are shown in Figure 7. These images were processed to produce the area coverage, size distribution, and number of Laves particles per unit area graphs shown in Figures 5, 8, and 9, respectively.

In Figure 5, the area coverage of Laves phase particles within individual images collected in positively (red) and negatively (black) segregated areas are compared with the distribution from the systematically collected random areas (blue). In the B2 sample, where the segregation has a banded structure, the extremes in the random distribution are similar to the coverages from the positively and negatively segregated regions. This is expected as the systematic random collection process will hit some positively and negatively segregated areas, but the majority will straddle the segregation bands and provide a natural compositional averaging effect. In the TP1 sample, although the negatively segregated area fits well with the lower tail of the systematically collected data set, the positively segregated area has much higher coverages than any images in the systematically collected data set. This is because the positive segregation in this sample is very localized and the systematic collection method used to collect the average data did not sample an extreme area of positive Mo segregation. This is important because if localized segregation is present in the steel, the sampling of these regions becomes a matter of chance and could consequently lead to misleading results where blind imaging strategies are used. An overall comparison of the Laves phase coverage from the data sets is shown in
Figure 9(a). This shows that the Laves phase coverage is on average 2.4 and 2.6 times higher in the positively segregated Mo areas of B2 and TP1, respectively, as compared to the corresponding negatively segregated Mo region.

Figure 8 shows the number of particles per unit area as a function of size for all data sets obtained for both samples. Consistently, the number of Laves phase particles per unit area is $>2 \mathrm{X}$ higher in the positively segregated Mo regions compared with the negatively segregated Mo regions as shown in Figure 9(b). The data collected from random locations sit in between these extremes. For the B2 sample, the data collected from random locations are at the mid-point between the extremes, whereas for TP1 they are located closer to the negatively segregated Mo point. This can be explained by the differences in the segregation characteristics of the samples, TP1 has localized enriched Mo 'clouds,' whereas B2 has a finer and much more ordered banded structure.

The size distribution data show that although the number of particles per unit area is much higher in positively Mo-segregated regions compared with negatively segregated regions, the size distribution of the particles is not significantly affected. This is important because this clearly shows that local increases of Mo result in increased nucleation of Laves phase particles but not an increased growth rate.

The amount of Laves phase as a function of temperature at thermodynamic equilibrium for these materials is predicted in Figure 10 using SEM-EDS compositions acquired from Figure 6 . This shows that at the service temperature of the components $\left(570^{\circ} \mathrm{C}\right)$, the level of Mo segregation observed (with SEM-EDS) would result in approximately a variation by a factor of 2 between the extremes in composition. The absolute range predicted at this temperature of approximately 0.6 to $1.2 \mathrm{vol}$ pct is consistent with the range in average area coverage values obtained by image analysis between the composition extremes in the samples ( 0.55 to 1.3 for $\mathrm{B} 2$ and 0.5 to 1.3 for TP1). Figure 10 shows that the predicted content of Laves phase decreases with increasing temperature for both samples and all compositions considered, and it also suggests at the creep test temperature $\left(625^{\circ} \mathrm{C}\right)$ there would be no Laves phase present in the negatively segregated regions. It is clear that this last point is not consistent with the observations documented in this investigation. Since the amount of Laves phase measured is consistent with the amount expected at thermal equilibrium at the service temperature, the relatively short creep tests at $625^{\circ} \mathrm{C}$ do not seem to have affected the Laves phase content of these materials. This is important as the thermodynamic driving force for the Laves phase particles to dissolve into the steel matrix appears to be a kinetically slow process.

Segregation effects could cause Laves phase particles to form in localized regions at higher temperatures where these particles tend to be coarser. This is important as large Laves phase particles have been 
Table IV. Quantitative Chemical Composition Data Acquired from Fig. 6 (SEM-EDS)

\begin{tabular}{|c|c|c|c|c|c|}
\hline \multirow{2}{*}{ Sample } & \multirow{2}{*}{ Area } & \multicolumn{4}{|c|}{ Concentration (Wt Pct) $\mathrm{Fe}=$ Balance } \\
\hline & & $\mathrm{V}$ & $\mathrm{Cr}$ & $\mathrm{Nb}$ & Mo \\
\hline \multirow[t]{4}{*}{$\mathrm{B} 2$} & high & 0.25 & 8.99 & 0.10 & 1.09 \\
\hline & low & 0.22 & 8.58 & 0.05 & 0.86 \\
\hline & average & 0.23 & 8.70 & 0.08 & 0.97 \\
\hline & XRF average & 0.16 & 9.02 & 0.06 & 0.82 \\
\hline \multirow[t]{4}{*}{ TP1 } & high & 0.27 & 8.61 & 0.12 & 1.10 \\
\hline & low & 0.21 & 8.02 & 0.05 & 0.84 \\
\hline & average & 0.22 & 8.25 & 0.07 & 0.89 \\
\hline & XRF average & 0.16 & 8.45 & 0.05 & 0.81 \\
\hline
\end{tabular}

Showing the variation of elements in positively (high), and negatively (low) Mo-segregated areas. Average composition measured using EDS and XRF (reproduced from Table III) are also included for comparison.
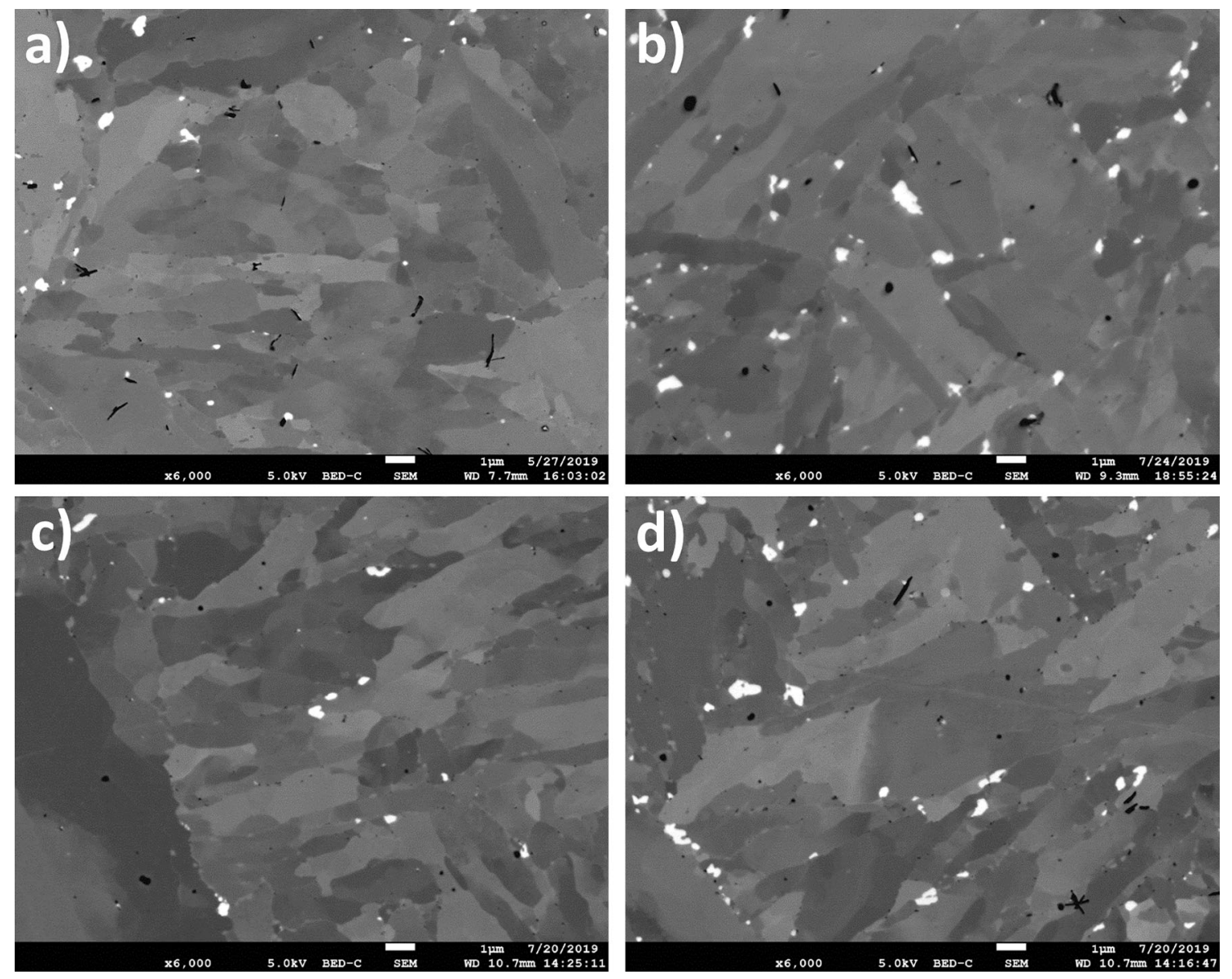

Fig. 7-Typical BSE-SEM images used for Laves phase quantification of B2 (a) and (b) and TP1 (c) and (d) for negatively (a) and (c) and positively (b) and (d) segregated areas.

reported to be possible nucleation sites for creep cavities in these steels, ${ }^{[12,18-20]}$ although it should be emphasized that direct evidence for this is lacking because of the high number density of these particles and the small size of the particles relative to creep cavities. However, the similarity in size distributions recorded here would suggest that, in these examples, the effect of segregation is to activate more nucleation sites in the steel, but not to accelerate diffusional growth once nucleated.

\section{CONCLUSIONS}

This study has shown that micro-segregation does have a significant effect on the quantification of Laves phase particles in martensitic CSEF steels. For two unique heats of Gr.91 steel, a factor of 1.24 to 1.38 difference in the Mo-content was present, resulting in a measured area coverage variability of $\sim 2.5 \times$ between positively and negatively segregated regions. The amount of Laves phase coverage in these regions 


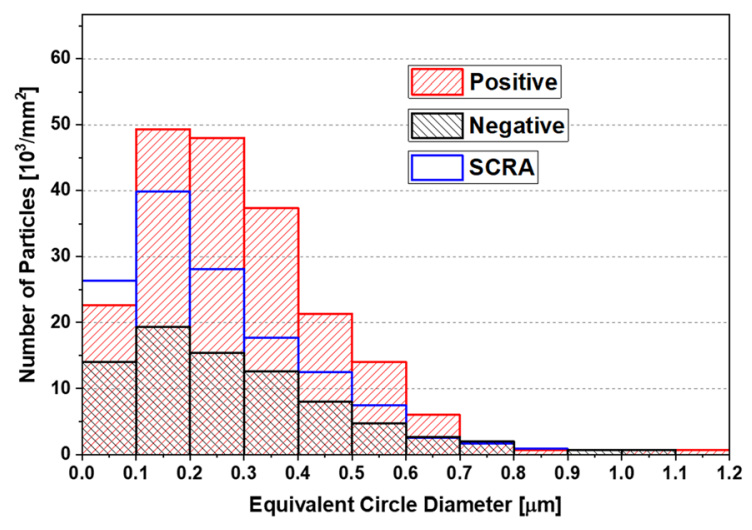

(a)

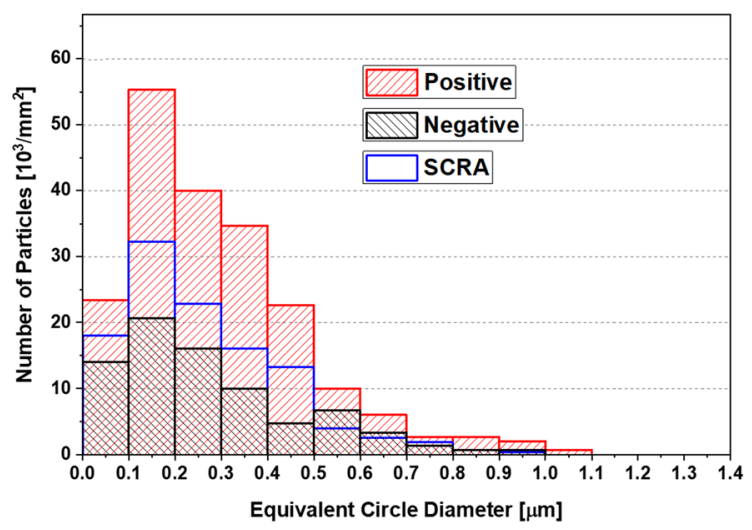

(b)

Fig. 8- Size distributions for the Laves phase particles for steels B2 (a) and TP1 (b) in positively (red), and negatively (black) Mo-segregated areas and systematically collected random areas (blue) (Color figure online).

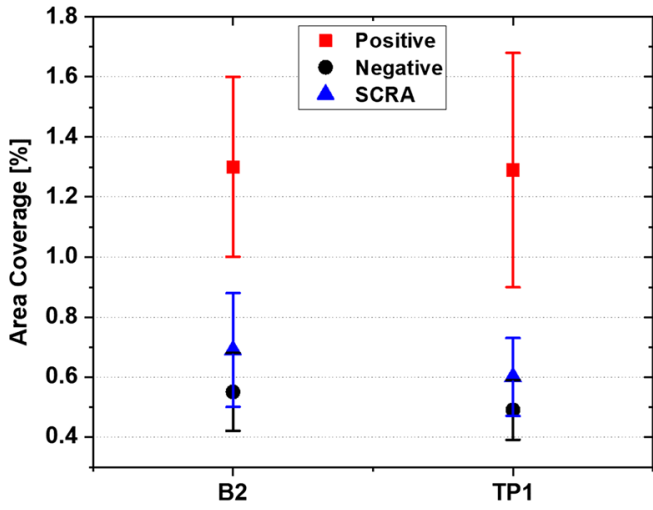

(a)

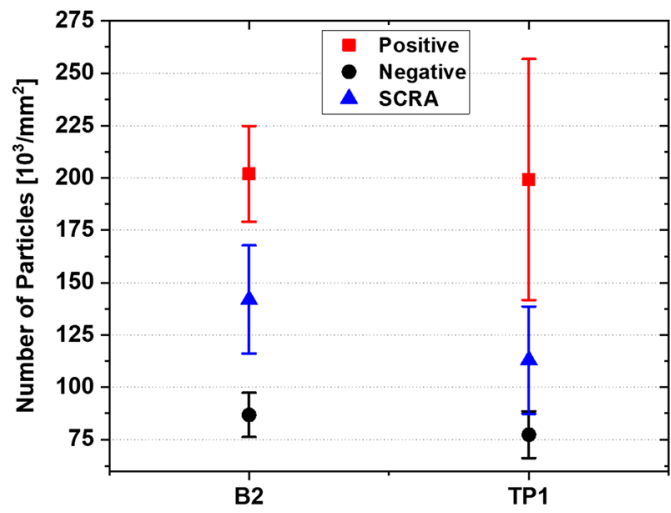

(b)

Fig. 9-Laves phase area coverage (a) and number of particles per unit area (b) for steels B2 and TP1 in positively (red), and negatively (black) Mo-segregated areas and systematically collected random areas (blue) (Color figure online).

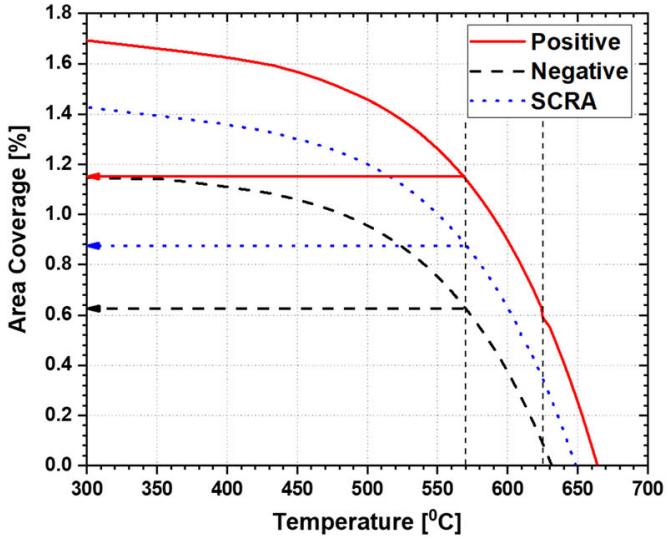

(a)

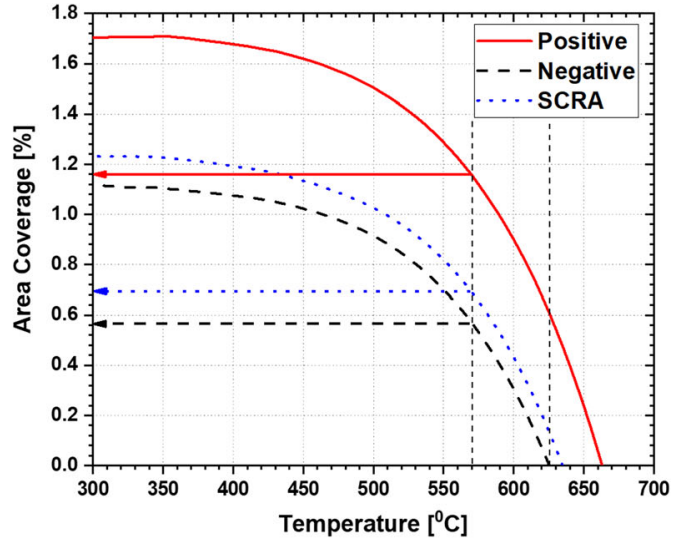

(b)

Fig. 10-Thermo-Calc simulations of the amount of Laves in positively (red), and negatively (black) Mo-segregated areas and systematically collected random areas (blue) for steel B2 $(a)$ and TP1 (b) (Color figure online).

agreed with the thermodynamic predictions for the local composition in the segregated regions and for the in-service temperature of $570^{\circ} \mathrm{C}$. This provides statistically significant evidence that composition segregation is the leading cause of area-to-area variation in the Laves phase particle number per unit area and phase coverage for both the Gr.91 materials studied in this work. 
The segregation characteristics are also shown to be linked to the product form. For the seamless pipe material, segregated bands were observed, whereas in the forged tee-piece, positively segregated non-directional diffuse 'clouds' are present. This means for the effects of segregation to be accounted for during quantification, the chemical homogeneity of the sample must be established. The use of creep test bars in this study reinforces the point that segregation effects are likely to be important in all creep studies for this material type.

Although this work has focused on just the intermetallic Laves phase particles, it has implications for all quantitative characterization. The distribution of inclusions and other second phase particles such as carbides, carbo-nitrides, nitrides, etc., will be dependent on the segregation characteristics of the material. Material failure and damage accumulation are most likely to occur at areas with a compositional extreme, for example, i) the highest population of inclusions, ii) the largest second phase particles, iii) the lowest number of MX particles, iv) a composition that provides a larger driving force for coarse particle precipitation, e.g., Laves or Z-phase. Consequently, the consideration of segregation is important when relating quantitative microstructural parameters to component life and add credibility to the need for informed and large-area mapping using the widely available electron microscopy tools demonstrated herein.

\section{ACKNOWLEDGMENTS}

The authors would like to thank the Electric Power Research Institute for their funding and continued support of this project.

\section{CONFLICT OF INTEREST}

The authors have no conflict of interest.

\section{OPEN ACCESS}

This article is licensed under a Creative Commons Attribution 4.0 International License, which permits use, sharing, adaptation, distribution and reproduction in any medium or format, as long as you give appropriate credit to the original author(s) and the source, provide a link to the Creative Commons licence, and indicate if changes were made. The images or other third party material in this article are included in the article's Creative Commons licence, unless indicated otherwise in a credit line to the material. If material is not included in the article's Creative Commons licence and your intended use is not permitted by statutory regulation or exceeds the permitted use, you will need to obtain permission directly from the copyright holder. To view a copy of this licence, visit http://creat ivecommons.org/licenses/by/4.0/.

\section{REFERENCES}

1. R. Viswanathan, K. Coleman, and U. Rao: Int. J. Press. Vessel. Pip., 2006, vol. 83, pp. 778-83.

2. J.R. Distefano, V. K. Sikka, J. J. Blass, C. R. Brinkman, J. M. Corum, J. A. Horak, R. L. Huddleston, J. F. King, R. W. McClung and W. K. Sartory: Summary of Modified 9Cr-1Mo Steel Development Program: 1975-1985, 1986, pp 9-287.

3. F. Masuyama and J.P. Shingledecker: Procedia Eng., 2013, vol. 55, pp. 314-25.

4. F. Masuyama: Adv. Heat Resist. Steel Power Gener., 1998.

5. T. Fujita: in 3rd Conference on Advances in Material Technology for Fossil Power Plants, 2001, pp. 33-65.

6. ASTM A335/A335M-19a, Standard Specification for Seamless Ferritic Alloy-Steel Pipe for High-Temperature Service, ASTM International, West Conshohocken, PA, 2019.

7. ASTM A213/A213M-19a, Standard Specification for Seamless Ferritic and Austenitic Alloy-Steel Boiler, Superheater, and Heat-Exchanger Tubes, ASTM International, West Conshohocken, PA, 2019.

8. ASTM A182/A182M-20, Standard Specification for Forged or Rolled Alloy and Stainless Steel Pipe Flanges, Forged Fittings, and Valves and Parts for High-Temperature Service, ASTM International, West Conshohocken, PA, 2020.

9. ASTM A217/A217M-20, Standard Specification for Steel Castings, Martensitic Stainless and Alloy, for Pressure-Containing Parts, Suitable for High-Temperature Service, ASTM International, West Conshohocken, PA, 2020.

10. X.Z. Zhang, X.J. Wu, R. Liu, J. Liu, and M.X. Yao: Mater. Sci. Eng. A, 2017, vol. 706, pp. 279-86.

11. J. Hald: Int. J. Press. Vessel. Pip., 2008, vol. 85, pp. 30-37.

12. C.G. Panait, W. Bendick, A. Fuchsmann, A.F. Gourgues-Lorenzon, and J. Besson: Int. J. Press. Vessel. Pip., 2010, vol. 87, pp. $326-35$.

13. M. Ortolani and P. Mariani: Mater. High Temp., 2016, vol. 33, pp. 604-08.

14. M.I. Isik, A. Kostka, and G. Eggeler: Acta Mater., 2014, vol. 81, pp. $230-40$.

15. K. Sawada, M. Takeda, K. Maruyama, R. Ishii, M. Yamada, Y. Nagae, and R. Komine: Mater. Sci. Eng. A, 1999, vol. 267, pp. 19-25.

16. G. Dimmler, P. Weinert, E. Kozeschnik, and H. Cerjak: Mater. Charact., 2003, vol. 51, pp. 341-52.

17. L. Korcakova, J. Hald, and M.A.J. Somers: Mater. Charact., 2001, vol. 47, pp. 111-17.

18. I. Fedorova, A. Belyakov, P. Kozlov, V. Skorobogatykh, I. Shenkova, and R. Kaibyshev: Mater. Sci. Eng. A, 2014, vol. 615, pp. $153-63$.

19. J.S. Lee, H. Ghassemi Armaki, K. Maruyama, T. Muraki, and H. Asahi: Mater. Sci. Eng. A, 2006, vol. 428, pp. 270-75.

20. Q. Li: Metall. Mater. Trans. A, 2006, vol. 37A, pp. 89-97.

21. P. Hofer, H. Cerjak, B. Schaffernak, and P. Warbichler: Steel Res., 1998, vol. 69, pp. 343-48.

22. K. Sawada, K. Sekido, K. Kimura, K. Arisue, M. Honda, N. Komai, N. Fukuzawa, T. Ueno, N. Shimohata, H. Nakatomi, K. Takagi, T. Kimura, K. Nomura, and K. Kubushiro: J. Iron Steel Inst. Japan, 2019, vol. 105, pp. 23-32.

23. B. Wang, H. Zhong, X. Li, X. Wang, T. Wu, Q. Liu, and Q. Zhai: Metals (Basel), 2019, vol. 9, pp. 249-62.

24. M.L. Santella, R.W. Swindeman, R.W. Reed, and J.M. Tanzosh: ASM Proc. Int. Conf. Trends Weld. Res., 2002, pp. 713-18.

25. G. Krauss: Metall. Mater. Trans. B, 2003, vol. 34B, pp. 781-92.

26. A. Ghosh: Sadhana Eng. Sci., 2001, vol. 26, pp. 5-24.

27. M. Basirat, T. Shrestha, G.P. Potirniche, I. Charit, and K. Rink: Int. J. Plast., 2012, vol. 37, pp. 95-107.

28. F. Wang, C. Davis, and M. Strangwood: Mater. Sci. Technol., 2019, vol. 35, pp. 615-27. 
29. D. Zhang and M. Strangwood: Mater. Sci. Technol., 2019, vol. 35, pp. $1337-46$.

30. S. Zheng, C. Davis, and M. Strangwood: Mater. Charact, 2014, vol. 95 , pp. 94-104.

31. C. Slater, A. Mandal, and C. Davis: Metall. Mater. Trans. B, 2019, vol. 50B, pp. 1627-36.
32. D. Chakrabarti, M. Strangwood, and C. Davis: Metall. Mater. Trans. A, 2009, vol. 40A, pp. 780-95.

Publisher's Note Springer Nature remains neutral with regard to jurisdictional claims in published maps and institutional affiliations. 